\title{
Virus-Enabled Synthesis and Assembly of Nanowires for Lithium Ion Battery Electrodes
}

Ki Tae Nam, ${ }^{1,4}$ Dong-Wan Kim, ${ }^{1} *$ Pil J. Yoo, ${ }^{2,4}$ Chung-Yi Chiang, ${ }^{1,5}$ Nonglak Meethong, ${ }^{1}$ Paula T. Hammond, ${ }^{2,4}$ Yet-Ming Chiang, ${ }^{1}$ Angela M. Belcher ${ }^{1,3,4,5} \dagger$

${ }^{1}$ Department of Materials Science and Engineering, ${ }^{2}$ Department of Chemical Engineering, ${ }^{3}$ Biological Engineering Division,

${ }^{4}$ Institute for Soldier Nanotechnologies, and ${ }^{5}$ Institute of Collaborative Biotechnology, Massachusetts Institute of Technology, Cambridge, MA 02139, USA.

*Present address: Materials Science and Technology Division, Korea Institute of Science and Technology, Seoul 136-791, Korea.

†To whom correspondence should be addressed. E-mail: belcher@mit.edu

Both materials selection and assembly are ongoing issues in the development of smaller, more flexible batteries. Cobalt oxide has shown excellent electrochemical cycling properties and it thus under consideration as an electrode for advanced lithium batteries. We use viruses to synthesize and assemble nanowires of cobalt oxide at room temperature. By incorporating gold binding peptides into the filament coat, we could form hybrid gold-cobalt oxide wires that improved battery capacity. Combining the virus templated synthesis at the peptide level and our methods for the control of two dimensional assembly of viruses on polyelectrolyte multilayers provides a systematic platform for integrating these nanomaterials to form thin, flexible lithium ion batteries.

There is an increasing need for smaller and flexible $\mathrm{Li}$ ion batteries and for methods to assemble battery materials. Nanoparticles, nanotubes $(1,2)$ and nanowires (3), as well as several assembly methods, using lithography, block copolymer (4), or layer-by-layer deposition (5), have been introduced for constructing dimensionally small batteries. In addition to their utility in nanoelectronics, there is also growing evidence that nanostructured materials can improve the electrochemical properties of $\mathrm{Li}$ ion batteries compared to their bulk counterparts (6). However, in order to attain this maximum potential, monodisperse, homogeneous nanomaterials and hierarchical organization control are needed. Bio-systems inherently have the molecular recognition and the capability of self assembly, thus are attractive template for constructing and organizing the nanostructure (7-13). We have previously used viruses to assemble semiconductor and magnetic nanowires $(14,15)$ and consider whether they can be used for device fabrication. Using batteries as our example device, we also explore whether the viruses can be modified to improve the electrode materials. As the viruses can assemble on multiple length scales, there may be scope for designing hierarchical self assembling batteries. For this biological approach, once the genes are programmed for a functional device, very little post synthesis processing is necessary. Additionally, this biological route uses room-temperature, aqueous synthesis conditions.

The M13 virus consists of approximately 2700 major coat proteins (p8) helically wrapped around its single stranded DNA, and of minor coat proteins (p3, p6, p7, and p9) at each end of the virus. The functionality of these subunit proteins can be modified specifically through additions in the M13 genome. Modification of the major coat proteins as well as minor coat proteins at the virus ends has been successfully demonstrated to form functional heterostructured templates for precisely-positioned nanomaterials $(16,17)$. Furthermore, the intrinsically anisotropic virus structures are well-suited for the growth of monodisperse, highly crystalline nanowires $(14,15)$. In addition, the anisotropic virus structures are promising as elements of well ordered nanostructure as demonstrated in 3D liquid crystal film $(18,19)$.

Predictive based design was used for engineering the virus to satisfy the multifunctional purpose of electrode formation and assembly with a polymer electrolyte for the Li ion battery (Fig. 1). Tetra-glutamate (EEEE-) was fused to the Nterminus of each copy of the major coat $\mathrm{p} 8$ protein with one hundred percent expression. This clone, named the E4 clone, was designed with three distinct purposes. First, it can serve as a general template for growing nanowires through the interaction of the glutamate with various metal ions. (Virus Biotemplating in Fig. 1). Carboxylic acid, the side chain of glutamate, binds positive metal ions via ion exchange, as demonstrated in polymeric templates (20). Glutamate is also believed to be important in biomineralization, as evident in its 
role in specific proteins that regulate the nucleation of biominerals in nature. Second, tetra-glutamate acts as a blocking motif for gold nanoparticles (21), due to the electrostatic repulsion. Therefore, tetra-glutamate reduces non-specific gold nanoparticle binding to phage, thereby increasing the specificity of a gold specific peptide to bind gold in low concentration. Lastly, the E4 clone is ideally suited for electrostatically driven assembly with a charged polymer (Assembly Engineering in Fig. 1). E4 is more negatively charged than wild type virus, enabling a favorable interaction with the positively charged electrolyte polymer. Zeta potential measurements of the $\mathrm{E} 4$ clone reveal a dramatic potential change between $\mathrm{pH} 4.5$ and $\mathrm{pH} 5.5$, thus enabling a certain degree of charge control.

To design the cobalt oxide nanowires electrodes, the E4 virus templates were incubated in aqueous cobalt chloride solution (1 mM) for $30 \mathrm{~min}$ at room temperature to promote cobalt ion binding (22). $\mathrm{Co}_{3} \mathrm{O}_{4}$ was chosen as one of a family of new lithium-active compounds with extremely large reversible storage capacity arising from displacement reactions (23), approximately three times larger than the capacity of carbon-based anodes currently used in commercial batteries. Following reduction with $\mathrm{NaBH}_{4}$ and spontaneous oxidation in water, monodisperse, crystalline cobalt oxide $\left(\mathrm{Co}_{3} \mathrm{O}_{4}\right)$ nanowire were produced (24). Figures 2A and 2B show transmission electron microscope (TEM) images of the virus templated $\mathrm{Co}_{3} \mathrm{O}_{4}$ nanowires, where $\mathrm{Co}_{3} \mathrm{O}_{4}$ nanocrystals of 2 3 $\mathrm{nm}$ in diameter were uniformly mineralized along the length of the virus. For TEM observation, a dilute suspension was dropped on a carbon coated TEM grid, washed with distilled water and dried. The high resolution TEM electron diffraction pattern and lattice spacing (Fig. 2) along with XRD confirms that the crystal structure is $\mathrm{Co}_{3} \mathrm{O}_{4}$. The figure $2 \mathrm{~B}$ inset shows that the measured lattice spacing corresponds to the planes of $\mathrm{Co}_{3} \mathrm{O}_{4}$. Because p8 proteins were genetically engineered with one hundred percent expression and cobalt ions have a strong binding affinity to the carboxyl groups of glutamate, homogeneous and high crystalline nanowires were synthesized. Furthermore, viral $\mathrm{Co}_{3} \mathrm{O}_{4}$ nanowires had a large surface area of $141.7 \mathrm{~m}^{2} / \mathrm{g}$ as measured by the BrunauerEmmett-Teller (BET) method. The mass ratio of $\mathrm{Co}_{3} \mathrm{O}_{4}$ and virus is 0.837:0.163. Contrary to $\mathrm{E} 4$ viruses, cobalt oxide nucleating viruses, solutions of wild type virus expressing no peptide insert or solutions without viruses formed irregular and large precipitates of $\mathrm{Co} / \mathrm{Co}_{3} \mathrm{O}_{4}$ mixtures.

For electrochemical evaluation of the cobalt oxide nanowires, positive electrodes were prepared by mixing together $3.29 \mathrm{mg}$ of the virus-based nanowires, Super $\mathrm{P}$ (MMM Carbon, Belgium) carbon black, and poly(vinylidene fluoride)-hexafluoropropylene (PVDF-HFP) binder in a mass ratio of 74:15:11. Swagelok design cells using Li metal foil used as the negative electrode and a separator film of Celgard 2400 were assembled and saturated with the liquid electrolyte, $1 \mathrm{M} \mathrm{LiPF}_{6}$ in ethylene carbonate and dimethyl carbonate (1:1 by volume). The assembled cells were galvanostically cycled between $3.0 \mathrm{~V}$ and $0.01 \mathrm{~V}$ using a MACCOR automated tester. Voltage/capacity curves (Fig. 2C) for the $\mathrm{Co}_{3} \mathrm{O}_{4} / \mathrm{Li}$ half cell showed similar behavior to $\mathrm{Co}_{3} \mathrm{O}_{4}$ nanoparticles produced by other methods (25). The larger first-insertion capacity compared to that in subsequent discharge is characteristic of this material, and is due to irreversible reactions occurring upon initial lithiation. Any biphasic nature (25) of $\mathrm{Co}_{3} \mathrm{O}_{4}$ and $\mathrm{Li}_{\mathrm{x}} \mathrm{Co}_{3} \mathrm{O}_{4}\left(\sim \mathrm{Li}_{1.47} \mathrm{Co}_{3} \mathrm{O}_{4}\right)$ at the early stages of discharge was not clearly evident from the voltage traces (Fig. 2C). We observed reversible capacity (Fig. 2D) ranging from 600 to $750 \mathrm{mAh} / \mathrm{g}$, which is about twice that of current carbon-based negative electrodes. The charge and discharge capacities stabilized at $600 \mathrm{mAh} / \mathrm{g}$ over 20 cycles. The reversible formation of $\mathrm{Li}_{2} \mathrm{O}$ accompanying the redox of cobalt nanoparticles and the reversible growth of a gel-like polymeric layer (26), resulting from electrolyte degradation, is believed to contribute to this reversible capacity. The existence of higher-than theoretical specific capacity in $\mathrm{Co}_{3} \mathrm{O}_{4}$ has been observed before (27) and it plausibly attributed to the reversible formation of a Li-bearing solid-electrolyte interface. At the nanometer scale, both the reversible formation of $\mathrm{Li}_{2} \mathrm{O}$, which is known to be electrochemically inactive in bulk, and the reversible formation of the gel-like layer catalyzed by cobalt nanoparticles, can occur (23). Control experiment revealed that the virus is electrochemically inactive and stable over the electrochemical conditions of our experiments as indicated by no decomposition evident in cyclic voltammograms (fig. S1). The virus capsid-mediated growth of uniform sized cobalt oxide nanomaterials, in addition to the structural integrity and dense packing (Fig. 2B) imparted by the virus, provides electrochemical advantages. For instance, controlling all other experimental conditions, samples fabricated without the virus templates exhibited rapidly fading capacity (Fig. 2D). This phenomenon, which is most likely attributable to incomplete oxidation of cobalt, inhomogeneous composition and large particle size, has also been observed for cobalt oxide prepared at low temperatures, in which high polarization is a contributing factor (25). However, the cobalt oxide nanowires, templated by M13 virus and oxidized spontaneously at room temperature, demonstrate comparable properties to particles fabricated at temperatures above $500^{\circ} \mathrm{C}$.

An added advantage of this system is that the nano-texture of viral $\mathrm{Co}_{3} \mathrm{O}_{4}$ nanowires can be manipulated by controlling the interactions between the peptides and cobalt ions. Higher cobalt chloride concentration (5 mM) with $10 \mathrm{mM} \mathrm{NaBH}_{4}$ produced branch-like nanowire structures (Fig. 2E); whereas, 
nucleation and growth of $\mathrm{Co}_{3} \mathrm{O}_{4}$ nanowires at $4^{\circ} \mathrm{C}$ with $1 \mathrm{mM}$ cobalt ion and $5 \mathrm{mM} \mathrm{NaBH}_{4}$ resulted in the assembly of discrete nanoparticles (Fig. 2F).

To design new hybrid material electrodes with higher capacity, additional material specific peptide motifs were engineered into the major coat p8 protein. This provides a general method for the systematic and controlled arrangement of two distinct nanomaterials, which can enhance the electrochemical properties through the cooperative contribution of each material. Increasingly, efforts to improve battery properties have focused on composite material design $(28,29)$. However, significant challenges such as the achievement of uniform distributions of multiple phases are encountered when components are combined at the nanoscale. Gold nanoparticles were chosen based on their ability to provide high electronic conductivity where needed, the ability to maintain a thermodynamically stable interface with $\mathrm{Co}_{3} \mathrm{O}_{4}$, and the potential to act as a chemical catalyst for electrochemical reactions at the nanoscale. We designed a bifunctional virus template that simultaneously expressed two different peptide motifs. To accomplish this, a gold-binding peptide motif (LKAHLPPSRLPS) was isolated through gold substrate screening using a phage display library (30), which contains random 12mer peptide sequences. Then, bifunctional viruses constructed to express both $\mathrm{Au}$ and $\mathrm{Co}_{3} \mathrm{O}_{4}$ specific peptides with the virus coat were assembled. Phagemid constructs (15) are inserted into host bacterial cells, encoding in this case for the gold-binding peptide motif (31). Thus, upon infection of the plasmid-incorporating host cells with the E4 virus, a small percentage of subsequent E4 p8 proteins also displayed the gold-specific peptide. Therefore, two types of p8 proteins were produced: intact p8 proteins of E4 viruses and engineered p8 proteins containing the gold-binding peptide motif, randomly packaged onto the virus progeny (Fig. 3A). This hybrid clone was named AuE4 virus. Incubation of the amplified AuE4 clones with a $5 \mathrm{~nm}$ gold colloid suspension ( $5 \times 10^{13}$ particles $/ \mathrm{mL}$, Ted Pella) resulted in one dimensional arrays of Au nanoparticles bound to the gold-binding peptides distributed among p8 proteins (Fig. $3 \mathrm{~B})$. In contrast, wild type viruses and the E4 virus which do not have gold binding motifs, did not bind gold nanoparticles along the length of the virus. After removing excess unbound gold nanoparticles by centrifugation, $\mathrm{Co}_{3} \mathrm{O}_{4}$ was nucleated and grown via the tetra-glutamate functionality, resulting in hybrid nanostructures of $5 \mathrm{~nm}$ Au nanoparticles spatially interspersed within the $\mathrm{Co}_{3} \mathrm{O}_{4}$ wires (Fig. 3C). The crystal structure of the $\mathrm{Co}_{3} \mathrm{O}_{4}$ was confirmed by electron diffraction. Inductively coupled plasma mass spectrometry (ICPMS) analysis indicated that $\mathrm{Au}$ nanoparticles were associated with $\mathrm{Co}_{3} \mathrm{O}_{4}$ in a mass ratio of 0.024:0.976.

The electrochemical properties of the hybrid $\mathrm{Au}-\mathrm{Co}_{3} \mathrm{O}_{4}$ nanowires were evaluated using galvanostatic cycling and cyclic voltammetry. The mass of $\mathrm{Au}-\mathrm{Co}_{3} \mathrm{O}_{4}$ nanowires deposited on the $\mathrm{Cu}$ substrate for one electrochemical cell was $3.41 \mathrm{mg}$. The virus-mediated hybrid composite generated higher initial and reversible lithium storage capacity than the pure $\mathrm{Co}_{3} \mathrm{O}_{4}$ nanowires when tested at the same current rate (Fig. 3D). The higher lithium storage capacity may result from the formation of Au-Li intermetallic compound or the conductive or catalytic effects of Au nanoparticles on the reaction of $\mathrm{Li}$ with $\mathrm{Co}_{3} \mathrm{O}_{4}$. $\mathrm{Au}$ is known to be electrochemically active, which leads to $\mathrm{Li}_{\mathrm{x}} \mathrm{Au}$ alloys (32). However, considering the $\mathrm{Au}: \mathrm{Co}_{3} \mathrm{O}_{4}$ ratio, it is believed that the contribution of $\mathrm{Li}_{\mathrm{X}} \mathrm{Au}$ alloys to the lithium storage capacity is negligible. Cyclic voltammetry (Fig. 3E) shows no significant new redox peaks that could be associated with the lithiation of $\mathrm{Au}$ (4). Considering the unique charging/discharging mechanism of $\mathrm{Co}_{3} \mathrm{O}_{4}$, wherein cobalt nanoparticles promote the reversible reaction of an organic layer that then contributes to the Li capacity, it is more likely that Au nanoparticles play a role in this displacement reaction. This role may be one of improving electronic conductivity to the $\mathrm{Co}_{3} \mathrm{O}_{4}$ nanoparticles, or it may be catalytic in nature. Indeed, decreased cell polarization was observed in the galvanostatic voltage-capacity curves, which could result from either of these mechanisms. Furthermore, $\mathrm{Au}$ incorporation clearly increases the reaction rate upon reduction of $\mathrm{Co}_{3} \mathrm{O}_{4}$ as indicated by the enhanced reduction peak seen by cyclic voltammetry in Fig. 3E (measured on samples of similar mass at the same voltage sweep rate). While the exact electrochemical mechanism is still under investigation, our results show that a small amount of $\mathrm{Au}$ nanoparticles dispersed within $\mathrm{Co}_{3} \mathrm{O}_{4}$ to produce a hybrid materials markedly improves electrochemical performance. The specific capacity of the hybrid is estimated to be at least $30 \%$ greater than that of our $\mathrm{Co}_{3} \mathrm{O}_{4}$ nanowires.

The principles of self assembly and biotemplating can be further extended to control virus-virus interactions for organizing nanostructured electrodes over large length scales. Recently, we observed that negatively charged M13 viruses can form very ordered, two dimensional liquid crystalline layers on top of electrostatically cohesive films of linear poly(ethylene imine) (LPEI)/poly(acrylic acid) (PAA) (33). The ordering of engineered viruses is driven by competitive electrostatic interactions, the interdiffusion of the polyelectrolyte, and the anisotropic shape of M13 viruses. By employing this technique to spontaneously order E4 viruses and subsequently grow $\mathrm{Co}_{3} \mathrm{O}_{4}$ on the virus coat proteins, two dimensional organized ensembles of nanowires were produced on a $10 \mathrm{~cm}$ length scale (Fig. 4, A and B). The spatial distance and ordering behavior between viral nanowires can be manipulated by controlling both surface charge and fluidic forces. Furthermore, the thickness of the multilayered polymer can be varied from $10 \mathrm{~nm}$ to several 
micrometers independent of the substrate. This assembly process produces light weight, flexible, and transparent active material/substrate multilayers, constructed as free standing films by a simple dipping method (Fig. 4C). This process should be scalable using roll-to-roll processing. Moreover, the polymer electrolyte is believed to act as a solid electrolyte because of the relatively fast ionic conductivity of LPEI and PAA pairs $(34,35)$. Thus the assembled layers comprise a negative electrode material grown upon a solid electrolyte or separator membrane. For electrochemical evaluation, $100 \mathrm{~nm}$ of $\mathrm{Cu}$, which functions as a current collector, was deposited by E-beam evaporation on the assembled $\mathrm{Co}_{3} \mathrm{O}_{4}$ nanowires/polymer layer. This assembly was then tested in Swagelok cells using a Li foil negative electrode separated from the multilayer by a liquid electrolyte dipped separator (36). Figure 4D shows the capacity for the assembled monolayer of $\mathrm{Co}_{3} \mathrm{O}_{4}$ nanowires/Li cell at two different charging rates. The cell was found to sustain and deliver $94 \%$ of its theoretical capacity at a rate of $1.12 \mathrm{C}$ and $65 \%$ at a rate of $5.19 \mathrm{C}$, demonstrating the capability for high cycling rate. We believe that the power of the cell can be further increased by alternating stacks of nanowire monolayers and polymer layers of LPEI and PAA or other polyions. In addition, the $\mathrm{Au}-\mathrm{Co}_{3} \mathrm{O}_{4}$ hybrid nanowires should also increase the total capacity.

The genetic approach presented for exploiting biomolecular interactions and self assembly at various length scales has technological potential in the development of electrodes for nanostructured devices. Our results demonstrate that these traditionally biological principles can be utilized for the rational design and assembly of nanoscale battery components, exhibiting improved performance in properties such as specific capacity and rate capability. The genetic control in the viral synthesis of monodisperse oxide nanowires and the nanoarchitecture of hybrid nanowires can be advanced through further modification of other proteins. Heterostructured nanowires, comprising anode and solid electrolyte, and bio-energy transducing nanowires, coupled with biomolecules, are currently being investigated.

Moreover, we anticipate that self-organized virus monolayers for the generation of anodic as well as cathodic materials on ionically conducting polyelectrolyte films may present potential architectures for interdigitated batteries (37). The ease of genetic modification allows for the growth and assembly of other functional nanomaterials for further application such photovoltaic devices, high surface area catalyst and supercapacitor.

\section{References and Notes}

1. A. S. Claye, J. E. Fischer, C. B. Huffman, A. G. Rinzler, R. E. Smalley, J. Elecrochem. Soc. 147, 2845 (2000).

2. J. S. Sakamoto, B. Dunn, J. Electrochem. Soc. 149, A26 (2002).
3. A. R. Armstrong, G. Armstrong, J. Canales, R. Garcia, P. G. Bruce, Adv. Mater. 17, 862 (2005).

4. S. C. Mui et al., J. Electrochem. Soc. 149, A1610 (2002).

5. T. Cassagneau, J. H. Fendler, Adv. Mater. 10, 877 (1998).

6. A. S. Aricò, P. Bruce, B. Scrosati, J-M. Tarascon, W. V. Schalkwijk, Nat. Mater. 4, 366 (2005).

7. S. Mann, Biominerallization: principles and concepts in bioinorganic materials chemistry (Oxford Univ. Press, New York, 2001).

8. A. M. Belcher et al., Nature 381, 56 (1996).

9. M. M. Murr, D. E. Morse, Proc. Nat. Acad. Sci. USA 102, 11657 (2005).

10. N. C. Seeman, Nature 421, 427 (2003).

11. S. Brown, Nat. Biotechnol 15, 269 (1997).

12. T. Douglas, M. Young, Nature 393, 152 (1998).

13. S. Zhang, Nat. Biotechnol. 21, 1171 (2003).

14. C. Mao and D. J. Solis et al., Science 303, 213 (2004).

15. C. Mao et al., Proc. Natl. Acad. Sci. U. S. A 100, 6946 (2003).

16. Y. Huang et al., Nano Lett. 5, 1429 (2005).

17. K. T. Nam, B. R. Peelle, S.-W. Lee, A. M. Belcher, Nano Lett. 4, 23 (2004).

18. S. W. Lee, C. Mao, C. Flynn, A. M. Belcher, Science 296, 892 (2002).

19. Z. Dogic, S. Fraden, Phys. Rev. Lett. 78, 2417-2420 (1997).

20. S. Joly et al., Langmuir 16, 1354 (2000).

21. B. R. Peelle, E. M. Krauland, K. D. Wittrup, A. M. Belcher, Langmuir 21, 6929 (2005).

22. The mass spectrum acquired by matrix assisted laser desorption/ionization (MALDI) confirmed that cobalt was bound with $\mathrm{p} 8$ proteins of $\mathrm{E} 4$ clones.

23. P. Poizot, S. Laruelle, G. Grugeon, L. Dupont, J-M. Tarascon, Nature 407, 496 (2000).

24. $100 \mu \mathrm{l}$ of $\mathrm{E} 4$ viruses $\left(10^{12}\right.$ phage $\left./ \mathrm{ml}\right)$ were incubated with $1 \mathrm{~mL}$ of $1 \mathrm{mM} \mathrm{CoCl}_{2} \cdot 6 \mathrm{H}_{2} \mathrm{O}$ for 1 hour. Then, $1 \mathrm{~mL}$ of 5 $\mathrm{mM} \mathrm{NaBH} \mathrm{H}_{4}$ was added and the solution was kept at room temperature for the further oxidation of nanowires.

25. D. Larcher, G. Sudant, J-B. Leriche, Y. Chabre, J-M. Tarascon, J. Electrochem. Soc. 149, A234 (2002).

26. J.-M. Tarascon et al., C. R. Chimie 8, 9 (2004).

27. Z. Yuan, F. Huang, C. Feng, J. Sun, Y. Zhou, Mater. Chem. Phys. 79, 1 (2003).

28. D. Gyu, B. Lestriez, D. Guyomard, Adv. Mater. 16, 533 (2004).

29. Z. P. Guo, E. Milin, J. Z. Wang, J. Chen, H. K. Liu, J. Electrochem. Soc. 152, A2211 (2005).

30. S. R. Whaley, D. S. English, E. L. Hu, P. F. Barbara, A. M. Belcher, Nature 405, 665 (2000).

31. Bacteria containing the engineered phagemids are inoculated into $20 \mathrm{ml}$ of Terrific Broth (TB) with Ampiclin (100 ug/ml). The culture was maintained at $37^{\circ} \mathrm{C}$ until 
mid-log phage ( $\left.\mathrm{OD}_{600} \sim 0.5\right) .10$ ul E4 bacteriophage and $20 \mathrm{ul}$ IPTG (100 mg/ml) were added into the bacteria culture. After 4.5 to $\sim 5$ hours incubation at $37^{\circ} \mathrm{C}$, phages were purified using regular purification procedure.

32. Binary Alloy Phase Diagrams, T. B. Massalski, H. Okamoto, P. R. Subramanian, L. Kacprzak, Eds., (ASM International, Materials Park, OH, 1990).

33. P. J. Yoo, et al., Nat. Mater. 5, 234 (2006).

34. D. M. DeLongchamp, P. T. Hammond, Chem. Mater. 15, 1165 (2003).

35. P. T. Hammond, Adv. Mater. 16, 1271-1293 (2004).

36. To prevent the oxidation of $\mathrm{Cu}$ after the deposition of $\mathrm{Cu}$ in vacuum, the sample was rapidly transferred to a glove box for the assembly of the battery. In fact, we could not observe the contribution of $\mathrm{CuO}$ in charging/discharging curve. The mass of cobalt oxide on the polymer is 22 $\mu \mathrm{g} / \mathrm{cm}^{2}$ measured by ICPMS.

37. J. W. Long, B. Dunn, D. R. Rolison, H. S. White, Chem. Rev. 104, 4463 (2004).

38. We thank S. K. Lee for engineering the E4 phage and S. T. Kottmann for the computer graphic work in Fig. 3A. This work was supported by the Army Research Office Institute of Collaborative Biotechnologies, the Army Research Office Institute of Soldier Nanotechnologies, and the David and Lucile Packard Foundation.

\section{Supporting Online Material}

www.sciencemag.org/cgi/content/full/1122716/DC1

Fig. S1

16 November 2005; accepted 24 March 2006

Published online 06 April 2006; 10.1126/science.1122716

Include this information when citing this paper

Fig 1. Schematic diagram of the virus enabled synthesis and assembly of nanowires as negative electrode materials for lithium ion batteries. Rationally designed peptide and/or materials specific peptides identified by biopanning were expressed on the major coat p8 proteins of M13 viruses to grow $\mathrm{Co}_{3} \mathrm{O}_{4}$ and $\mathrm{Au} / \mathrm{Co}_{3} \mathrm{O}_{4}$ nanowires. Macroscopic ordering of the engineered viruses was utilized for fabricating an assembled monolayer of $\mathrm{Co}_{3} \mathrm{O}_{4}$ nanowires for flexible, light weight Li ion batteries.

Fig 2. Characterization of the $\mathrm{M} 13$ virus templated $\mathrm{Co}_{3} \mathrm{O}_{4}$ nanowires. (A) TEM image of virus templated $\mathrm{Co}_{3} \mathrm{O}_{4}$ nanowires. For visualizing the individual wires, the nanowires solution was diluted by 1:100. (B) High resolution TEM image of a $\mathrm{Co}_{3} \mathrm{O}_{4}$ viral nanowire. Electron diffraction pattern (Inset, upper right) confirmed that the crystal structure is $\mathrm{Co}_{3} \mathrm{O}_{4}$. Magnified image (Inset, lower right) shows the lattice fringe of $\mathrm{Co}_{3} \mathrm{O}_{4}$ nanocrystals along the major coat p8 proteins of a virus. The measured lattice spacing corresponds to the (311) and (400) planes of $\mathrm{Co}_{3} \mathrm{O}_{4}$. (C) Chargingdischarging curves for a virus meditated $\mathrm{Co}_{3} \mathrm{O}_{4} / \mathrm{Li}$ half cell cycled between $3 \mathrm{~V}$ and $0.01 \mathrm{~V}$ at a rate of $\mathrm{C} / 26.5$. C was defined as eight Li per hour. (D) Specific capacity vs. cycle number for the same cell. The mass of just $\mathrm{Co}_{3} \mathrm{O}_{4}$ was considered. For comparison, the data for the powder which was fabricated without viruses at the same condition are shown. (E) TEM images of differently nanostructured $\mathrm{Co}_{3} \mathrm{O}_{4}$ viral nanowires which were fabricated at higher cobalt ion concentration. (F) TEM images of the assembly of the discrete $\mathrm{Co}_{3} \mathrm{O}_{4}$ nanocrystals (on the p8 proteins) which were synthesized at $4{ }^{\circ} \mathrm{C}$.

Fig 3. Characterization of hybrid nanostructure of $\mathrm{Au}$ nanoparticles incorporated $\mathrm{Co}_{3} \mathrm{O}_{4}$ nanowires. (A) Visualization of the genetically engineered M13 bacteriophage viruses. P8 proteins containing gold binding motif (yellow) was doped by the phagemid method in E4 clones which can grow $\mathrm{Co}_{3} \mathrm{O}_{4}$. (B) TEM images of the assembled gold nanoparticles on the virus. Control experiments proved that gold nanoparticles were bound by the gold specific peptides. (C) TEM image of hybrid nanowires of $\mathrm{Au}$ nanoparticles $/ \mathrm{Co}_{3} \mathrm{O}_{4}$. (D) Specific capacity of hybrid $\mathrm{Au}-\mathrm{Co}_{3} \mathrm{O}_{4}$ nanowires. Half cell with $\mathrm{Li}$ electrode was cycled with a rate of $\mathrm{C} / 26.5$. Virus mass was subtracted and the mass of active materials such as $\mathrm{Co}_{3} \mathrm{O}_{4}$ and $\mathrm{Au}$ was counted. The capacity of virus directing $\mathrm{Co}_{3} \mathrm{O}_{4}$ nanowires without Au nanoparticles was also compared. (E) Cyclic voltammograms of hybrid $\mathrm{Au}-\mathrm{Co}_{3} \mathrm{O}_{4}$ and $\mathrm{Co}_{3} \mathrm{O}_{4}$ nanowires at a scanning rate of $0.3 \mathrm{mV} / \mathrm{s}$.

Fig 4. Two dimensional assembly of $\mathrm{Co}_{3} \mathrm{O}_{4}$ nanowires driven by liquid crystalline ordering of the engineered M13 bacteriophage viruses. (A) and (B) Phase mode AFM image of macroscopically ordered monolayer of $\mathrm{Co}_{3} \mathrm{O}_{4}$ coated viruses. Z-range is $30^{\circ}$ (C) Digital camera image of a flexible and transparent free standing film of (LPEI/PAA) $)_{100.5}$ on which $\mathrm{Co}_{3} \mathrm{O}_{4}$ viral nanowires are assembled into nanostructured monolayer with dimension of $10 \mathrm{~cm} \mathrm{x} 4 \mathrm{~cm}$. (D) Capacity for the assembled monolayer of $\mathrm{Co}_{3} \mathrm{O}_{4}$ nanowires/Li cell at two different charging rate. 


\section{Virus Biotemplating}

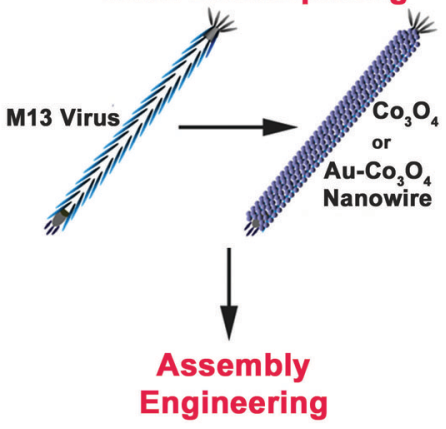

Macroscopic Self Assembly of Virus
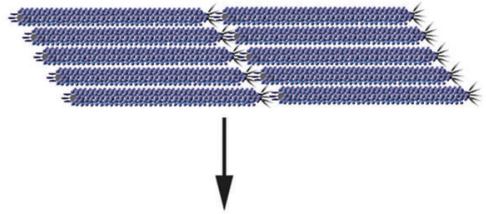

\section{Li Ion Battery}

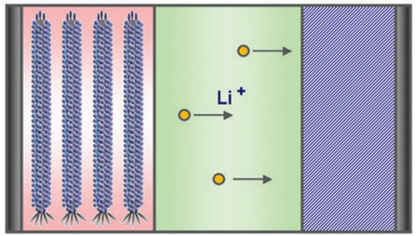

Anode

Electrolyte Cathode 

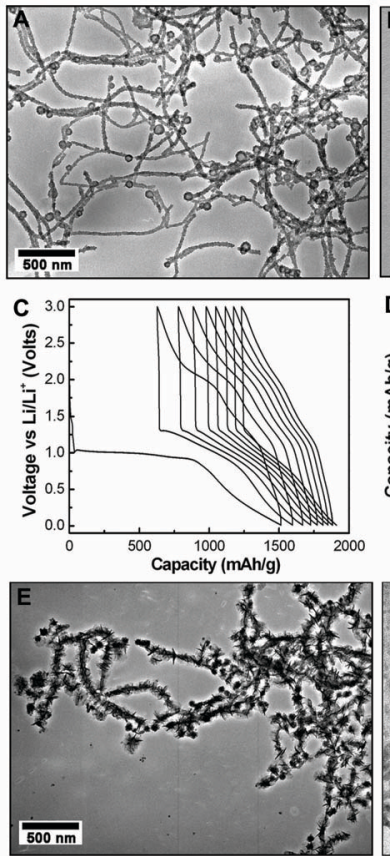
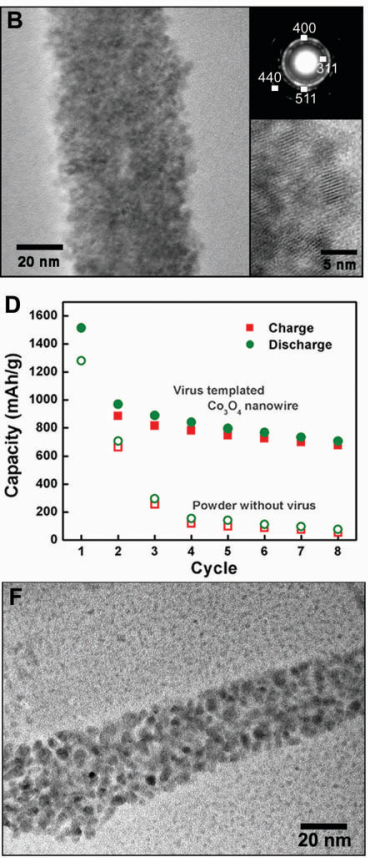
A

Co nucleating motif (EEEE)

\section{Au binding motif (LKAHLPPSRLPS)}
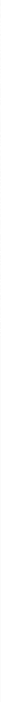


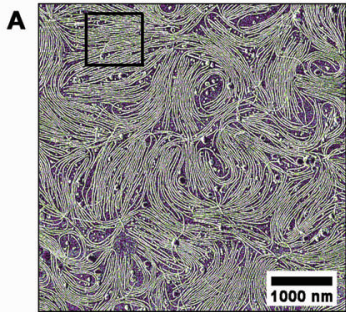

B
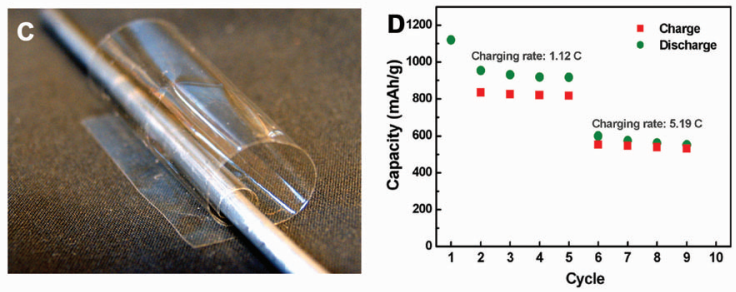